\title{
Research of 2-D Variable Exhaust Nozzle
}

\author{
Kimihiro Kishi ${ }^{1}$ and Hugues Joubert ${ }^{2}$ \\ ${ }^{1}$ Commercial Aero Engine Department \\ Aerospace Systems, Guidance \& Propulsion Division \\ Mitsubishi Heavy Industries, Ltd. \\ 1200, Higashi-Tanaka, Komaki City, Aichi Pref., 485-8561, JAPAN \\ E-mail: kimihiro_kishi@mhi.co.jp \\ FAX: +81-568-79-4348 \\ ${ }^{2}$ SNECMA, FRANCE
}

\begin{abstract}
Exhaust nozzle research was conducted to develop design technologies for propulsion system of Hypersonic transport. According to engine cycle study, nozzle cross sectional area should be variable for nozzle pressure ratio up to 270 level. Thrust coefficient should be 0.95 to meet $2.0 \mathrm{~kg} / \mathrm{hr} / \mathrm{kg}$ of SFC at Mach 5 . And nozzle liner have to endure $1900^{\circ} \mathrm{C}$ level gas temperature. So exhaust nozzle is to have two dimensional (2-D) variable geometry and cooling structure.

Aerodynamic study was conducted by model test and CFD. As result, target thrust coefficient was achieved. Variable geometry mechanism is designed to have convergent/divergent flaps and side walls. Convergent/divergent flaps are separated to introduce ambient air from throat into inside of nozzle at take-off. Integrated film and impingement cooling structure is designed using composite for liner based on heat transfer coefficient distribution and cooling efficiency, acquired by model test. This paper describes 2-D Variable Exhaust Nozzle Research.
\end{abstract}

\section{NOMENCLATURE}

$\begin{array}{lll}\mathrm{B.L} . & = & \text { Boundary Layer } \\ \mathrm{C}_{\mathrm{f}} & = & \text { Thrust Coefficient } \\ \mathrm{C}_{\mathrm{d}} & = & \text { Flow Discharge Coefficient } \\ \mathrm{Pr} & = & \text { Prandtl Number } \\ \mathrm{Tad} & = & \text { Adiabatic Wall Temperature } \\ \mathrm{Tb} & = & \text { Bulk Temperature } \\ & & \text { (Averaged Mixture Temperature) } \\ \mathrm{Tc} & = & \text { Cooling Air Temperature } \\ \mathrm{To} & = & \text { Main Flow Temperature } \\ \mathrm{Tt} & = & \text { Total Temperature } \\ \mathrm{Tw} & = & \text { Nozzle Wall Temperature }\end{array}$

$\begin{array}{lll}\mathrm{M} & = & \text { Mach number } \\ \alpha & = & \text { Heat Transfer Coefficient } \\ \eta_{\mathrm{c}} & = & \text { Cooling Efficiency } \\ \lambda & = & \text { Thermal Conductivity } \\ (\partial \mathrm{T} / \partial \mathrm{n})_{\mathrm{w}} & = & \text { Temperature gradient perpendicular to wall }\end{array}$

\section{INTRODUCTION}

Hypersonic Transport Propulsion System Research (HYPR) Project has been conducted from 1989 to 1999, in order to develop the technologies for propulsion system of Mach 5 hypersonic civil transport (HST). Figure.1 shows conceptual drawing of proposed propulsion system [1]. This system is requested to meet high economic and environmental requirements.

Exhaust nozzle system is one of key components to make the propulsion system operate efficiently in wide range from take-off to Mach 5 cruise. So exhaust nozzle should be designed to attain requested thrust coefficient and to reduce jet noise.

Target of the research is to attain thrust coefficient more than 0.95 at Mach 5 cruise in ram mode condition as well as 0.97 Mach 3 cruise in turbo mode. Therefore the nozzle should have two dimensional convergent/divergent configuration and variable geometry mechanism, in order to accommodate cross-sectional area, cooling structure to endure against high temperature gas condition up to $1900^{\circ} \mathrm{C}$ at Mach 5, furthermore, noise suppressor to reduce exhaust jet noise level at take-off.

Considering these features and requirements, exhaust nozzle research is proceeded with such technical areas as aerodynamics including variable geometry mechanism with noise suppressor and Cooling structure, by performing sub scaled model tests and CFD.

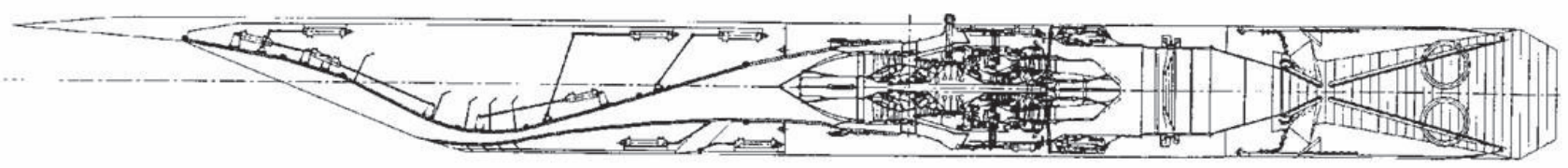

Fig.1 Conceptual Drawing of Mach 5 HST Propulsion System

Manuscript received on November 7, 2012

Review completed on December 2, 2013 


\section{AERODYNAMIC PERFORMANCE}

In order to develop aerodynamic design technologies, Ram Nozzle Research has been conducted by CFD calculations and sub scale model test at ONERA facilities in France simulating Mach 5 cruise condition at ram mode.

In this research, at first two candidates are considered for target nozzle configuration. The one is straight divergent flaps (Nozzle A), and another is characteristic curved ones (Nozzle B). In order to determine aerodynamic contours of both nozzles at Mach 5 condition, i.e. design point, parametric studies have been conducted using 2D(two dimensional)-Euler code by SNECMA with MHI [2]. Major parameters are convergent flap angle, throat wall radius, and divergent flap angle [3]-[5].

The approach was based on a step by step methodology, governing by the following main rules.

(1) Progressive used of reliable and accurate numerical tools

$\rightarrow$ 2D Euler + Boundary Layer(B.L.) correction

$\rightarrow 2 \mathrm{D}$ NS (Navier Stokes)

$\rightarrow 3 \mathrm{D}$ Euler

$\rightarrow 3 \mathrm{D} \mathrm{NS}$

These tools are used under the following purposes.

1) $2 \mathrm{D}$ Euler + B.L. correction

The first step of the study is to evaluate the main geometrical design parameter influences on flow discharge and thrust coefficients. The geometrical parameters are the convergent flap angle, throat curvature radius, and divergent flap contour (straight and curved), angles and length. 2D Euler + BL correction method is considered useful for this purpose from a simple method point of view.

2) $2 \mathrm{D} \mathrm{NS}$

Chemical gas reaction inside the convergent and divergent nozzle is not considered, however the effect of temperature on real gas law is assessed by 2D NS calculation.

3) 3D Euler

3D calculation is focused on 3D effect especially cruise condition. 3D mesh is generated CATIA modeling and 3D Euler code is used to optimize the mesh shape and size.

4) 3D NS

The detail analysis of flow discharge and thrust coefficients are carried out using 3D NS computation and are verified through the wind tunnel test by small scaled model.

(2) Cruise Optimization (Mach 5) and assessment of the climbing performances (Mach 3)

(3) Nozzle design from upward to backward

Performance of each nozzle is measured through the two computed coefficients as follows (1) and (2).

Thrust coefficient : Cf

$$
\mathrm{Cf}=\text { actual thrust }(\text { exit area }) \div \text { ideal thrust } *
$$

* Provided by actual mass flow in full expansion and with real gas assumption.

Flow discharge coefficient : $\mathrm{Cd}$

$\mathrm{C}_{\mathrm{d}}=$ actual mass flow (at throat $) \div$ ideal $1 \mathrm{D}$ mass flow
The thrust coefficient and flow coefficient performance of Mach 5 configuration and Mach 3 one as off design point have been analyzed and compared with each other by 2D-NScode.

As a result it is found that both nozzle will achieve target thrust coefficient and that curved one is superior to straight one at Mach 5 point, but at Mach 3 point vice versa. Figure 2 and Table 1 show the results of CFD calculation.

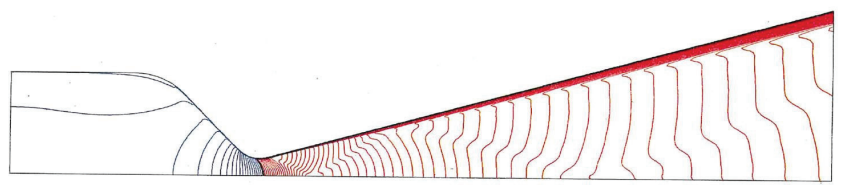

(a) Nozzle A (Straight Flap)

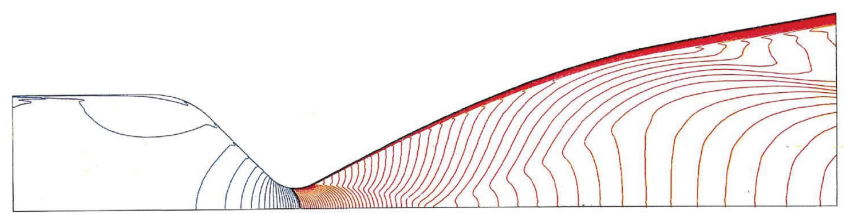

(b) Nozzle B (Curved Flap)

Fig.2 Mach contour by 2D-NS computation

Table 1 CFD calculation results

\begin{tabular}{|c|c|c|c|}
\hline Condition & Type & Cd & Cf \\
\hline \multirow{2}{*}{$\begin{array}{c}\text { Euler + B.L. } \\
\text { (Mach3) }\end{array}$} & Nozzle A & 0.993 & 0.996 \\
\cline { 2 - 4 } & Nozzle B & 0.992 & 0.967 \\
\hline \multirow{2}{*}{$\begin{array}{c}\text { Euler + B.L. } \\
\text { (Mach 5) }\end{array}$} & Nozzle A & 0.991 & 0.987 \\
\cline { 2 - 4 } & Nozzle B & 0.991 & 0.992 \\
\hline $\begin{array}{c}\text { 2D-NS } \\
\text { (Mach 5) }\end{array}$ & Nozzle A & 0.991 & 0.974 \\
\cline { 2 - 4 } & Nozzle B & 0.990 & 0.981 \\
\hline
\end{tabular}

In this research curved one is selected making much of Mach 5 performance. 3D-NS calculations predicted that curved one can attain target performance more than 0.9 point of thrust coefficient at Mach 5 condition and estimated flow coefficient, static pressure distribution on inner wall and local velocity. Figure 3 shows results of 3D-NS computation.

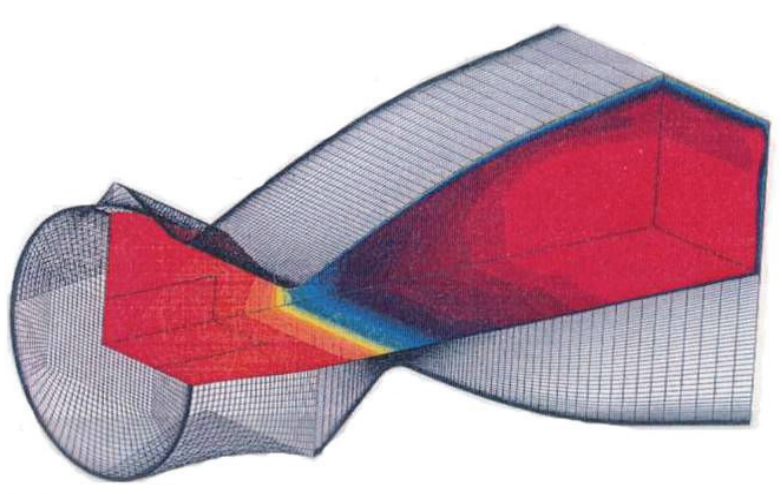

Fig.3 Mach contour by 3D-NS computation 
Based on this analyses sub-scale model has designed and manufactured by SNECMA and tested at ONERA S4B test stand on Jan. 1993. The test results encouraged that CFD calculation result was well agreed with them and available to nozzle aerodynamic design and analyses. Figure 4 shows ONERA test model. Figure 5 shows thrust coefficient $(\mathrm{Cf})$ and flow coefficient $(\mathrm{Cd})$ performance prediction of ram mode condition.

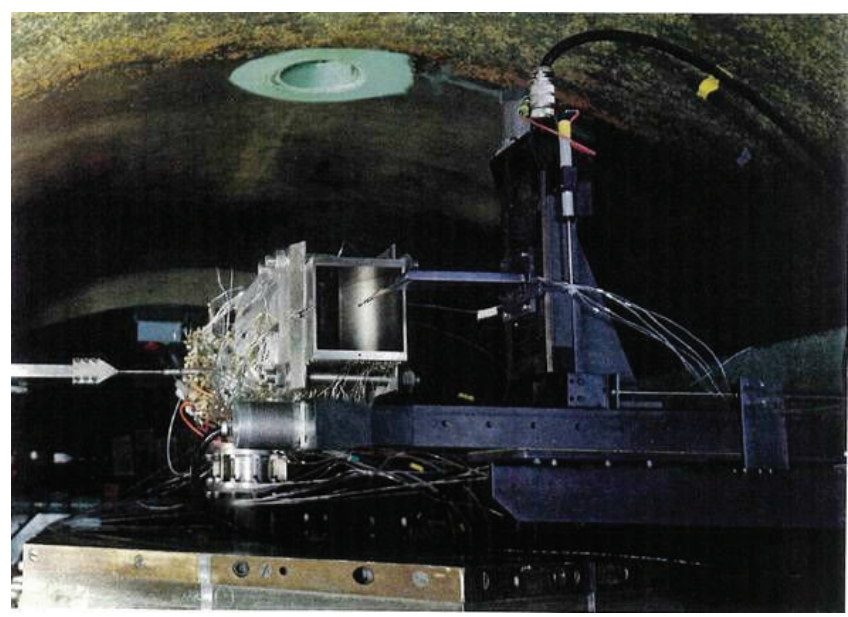

Fig.4 ONERA Test model

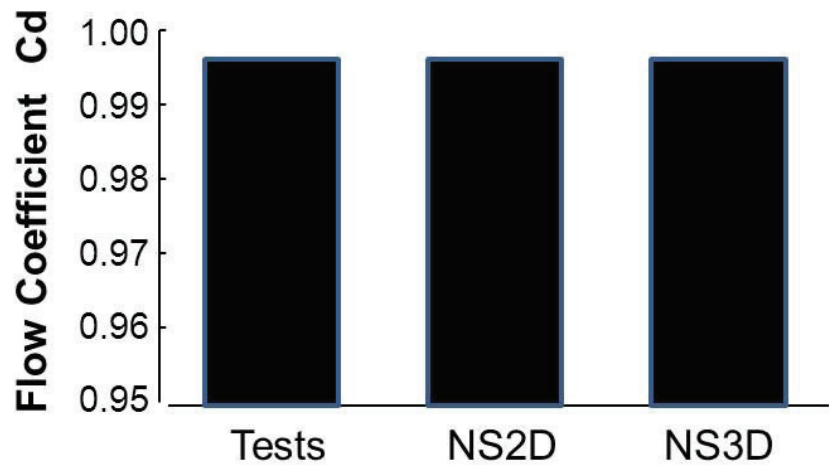

(a) Flow Coefficient

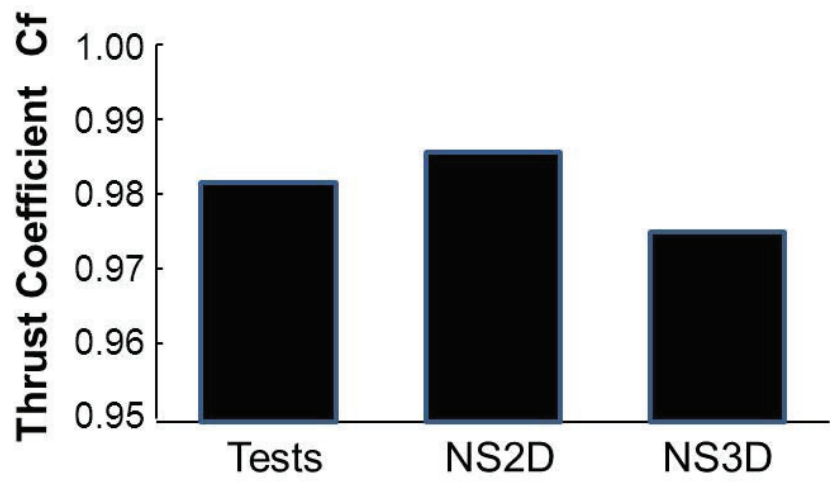

(b) Thrust Coefficient

Fig.5 Nozzle Performance Prediction

So finally thrust coefficients at Mach 3 and Mach 5 condition are evaluated based on CFD calculation and model test results as showed in Figure 6 [6]. Curved flap nozzle is better performance at Mach 5 mode rather than Straight flap, however from the manufacturing and cost performance point of view, Straight flap will be better than Curved flap. And Straight flap will be achieved the target both at Mach 3 and Mach 5. So final configuration is selected as Straight flap here and after.

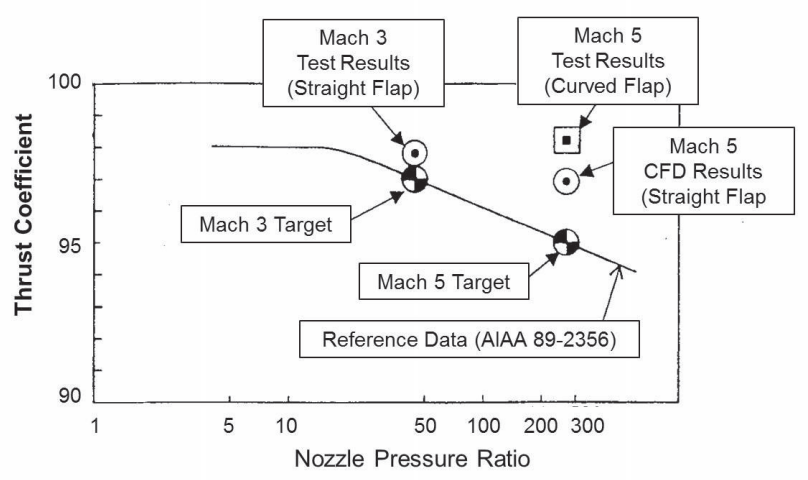

Fig. 6 Evaluation of Thrust Coefficient

\section{COOLING STRUCTURE}

In order to develop cooling structure design technologies, heat transfer test and sub-scale cooling model tests have been conducted. Heat transfer test is to acquire heat transfer coefficient distribution data on nozzle inner wall using sub-scale nozzle model manufactured and tested by Mitsubishi Heavy Industries (MHI).

Heat transfer coefficient is predicted using CFD calculation. It is calculated by 2D-NS analysis and the equation of heat transfer coefficient is provided as follows (3).

This calculation is based on the isothermal condition on the wall surface.

$$
\alpha=-\lambda \frac{(\partial \mathrm{T} / \partial n) w}{\mathrm{Tw}-\mathrm{Tad}}
$$

where Tw and Tad are wall temperature and adiabatic wall temperature respectively.

$(\partial \mathrm{T} / \partial \mathrm{n})_{\mathrm{w}}$ is temperature gradient which is perpendicular to wall, and $\lambda$ is thermal conductivity on the wall surface. Tad is provided by the following equation (4).

$$
\operatorname{Tad}=\operatorname{Tb}\left\{1+\operatorname{Pr}^{0.5}\left(\frac{T t}{T b}-1\right)\right\}
$$

where Pr is Prandtl Number, Tb and Tt are Bulk Temperature (Averaged Mixture Temperature) and Total Temperature respectively.

Figure 7 shows heat transfer test stand and model. This model is about $1 / 20$ level subscale. The data measurement is static wall pressure and temperature. The heat transfer distribution is measured using calorie meter method by air blow down.

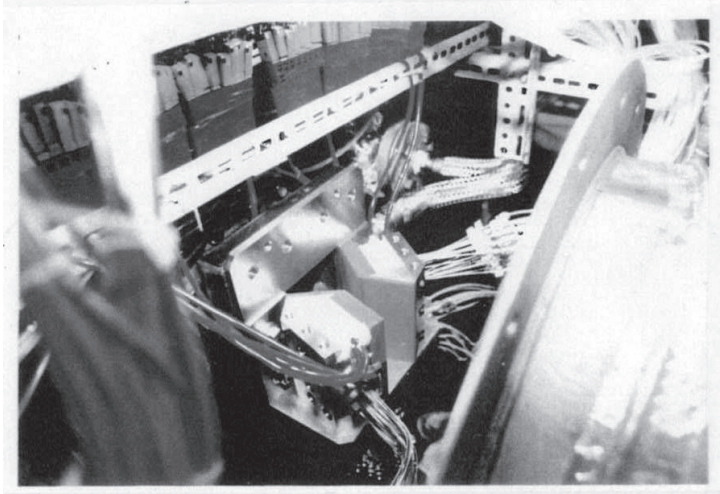

Fig.7 Heat transfer test model 
Figure 8 shows the test data of heat transfer coefficient distribution. The test results show peaks of heat transfer appear around nozzle throat. The heat transfer coefficient will be 2000 $\mathrm{w} / \mathrm{m}^{2} / \mathrm{K}$ level at throat and twice to 4 times larger than inlet and exit potion. So it is necessary to cool the liner around throat portion. And Prediction of heat transfer using CFD is slightly larger than test data around convergent area between inlet and throat and agreed with divergent area after throat to exit. So it is considered to be useful this prediction for the application of design purpose.

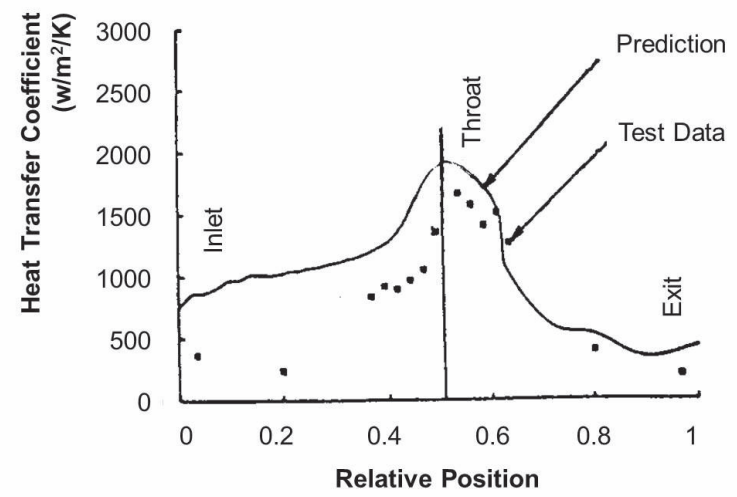

Fig. 8 Heat transfer data

Based on the results of heat transfer data, the cooling structure design has been proceeded. Material Candidates for nozzle cooling liner were given as carbon/carbon composite $(\mathrm{C} / \mathrm{C})$ or ceramic matrix composite (CMC). Material characteristics have been tested in Advanced Material Research in another program of HYPR program. Based on material test results at current technology, maximum allowable liner temperature will be $1500^{\circ} \mathrm{C}$ level. Within the temperature, surface condition, mechanical property and weight loss are considered to be acceptable. So cooling structure has been designed to make liner temperature lower than $1500^{\circ} \mathrm{C}$ under $1900^{\circ} \mathrm{C}$ of maximum gas temperature condition using $\mathrm{C} / \mathrm{C}$ or CMC material.

As a result, Cooling Structure is considered to be an integrated film and impingement scheme as shown in Figure 9 [6]-[8].

Cooling air will be introduced form the exit of Ram Combustor cooling air or made use of Intake bleed. The cooling air flow rate will be required to be $15 \%$ of Main Gas Flow and the air temperature is assumed around $1000^{\circ} \mathrm{C}$ level or lower. Cooling air will be introduced between main plate and liner. The liner has 0.5 $\mathrm{mm}$ or $1.0 \mathrm{~mm}$ size of impingement cooling hole. As for the film cooling, $0.5 \mathrm{~mm}$ or $1.0 \mathrm{~mm}$ size of hole or slit will be arranged by $200 \mathrm{~mm}$ pitch and discharge angle will be around $30^{\circ}$ on liner surface. After the cooling air is impinged on to back side of liner, it will be discharged and will cool the surface of inside of liner as a film cooling air.

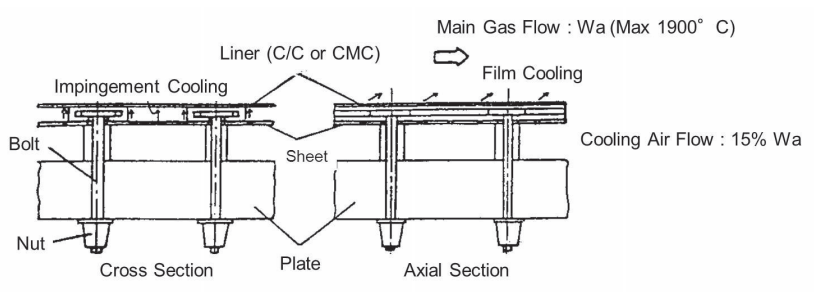

Fig.9 Cooling structure concept

On the other hand, cooling structure is required to perform cooling effect without spoiling the thrust coefficient. So it is necessary to minimize cooling requirements and to inject film air onto liner not to disturb inner flow as well as keep the required cooling effect. For evaluating cooling design procedure and cooling efficiency performance, a sub-scale cooling model tests have been carried out. Figure 10 shows basic model of cooling structure test.

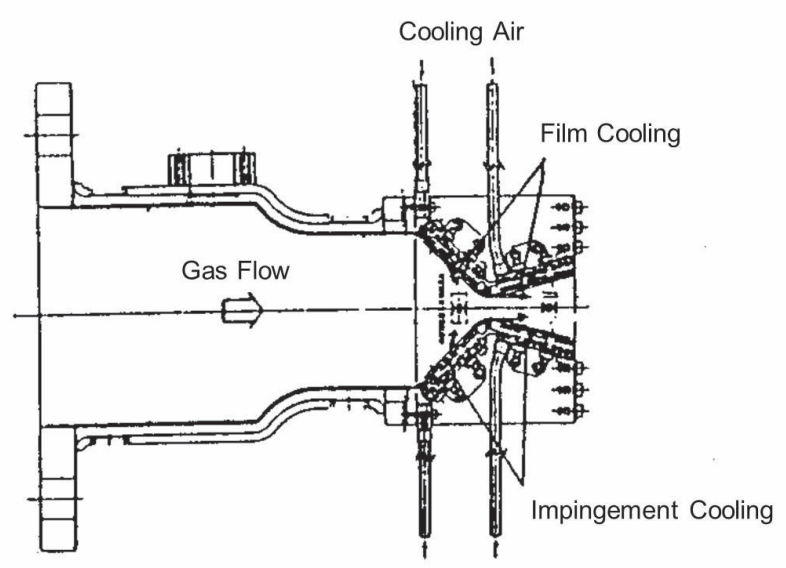

Fig.10 Cooling structure model test

This model has also integrated impingement and film cooling structure. This model is approximately $1 / 20$ size scale of target configuration. Due to the restriction of test facility, the divergent portion is truncated, so the test is focus on convergent and throat portion (5).

The cooling efficiency $\eta_{c}$ is provided by the following equation

$$
\eta c=\frac{\mathrm{To}_{\mathrm{o}}-\mathrm{Tw}}{\mathrm{To}-\mathrm{Tc}}
$$

As a result it is found that cooling performance will be achieved. And the prediction has good agreement with model test results as shown in Figure 11.

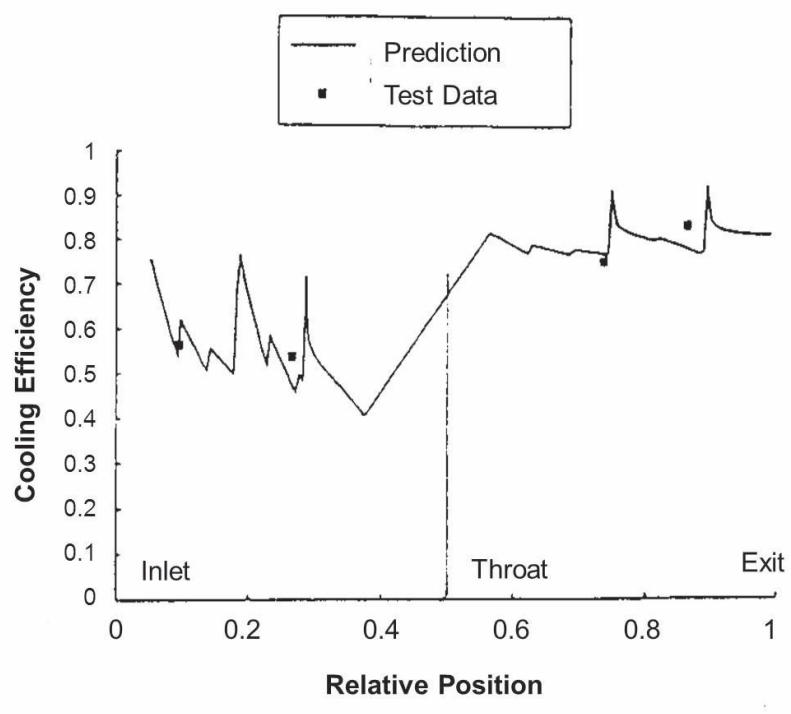

Fig.11 Cooling performance data 
Based on these results nozzle liner temperature is predicted as shown in Figure 12.

Maximum temperature of liner of the convergent flap will be $1543^{\circ} \mathrm{C}$ and that of divergent flap will be $1531^{\circ} \mathrm{C}$. The temperature at throat portion is predicted lower than Maximum temperature besides the heat transfer coefficient is larger than other portion. This results show that cooling structure will meet the cooling requirement to endure $1900^{\circ} \mathrm{C}$ level gas temperature at Mach 5 condition.

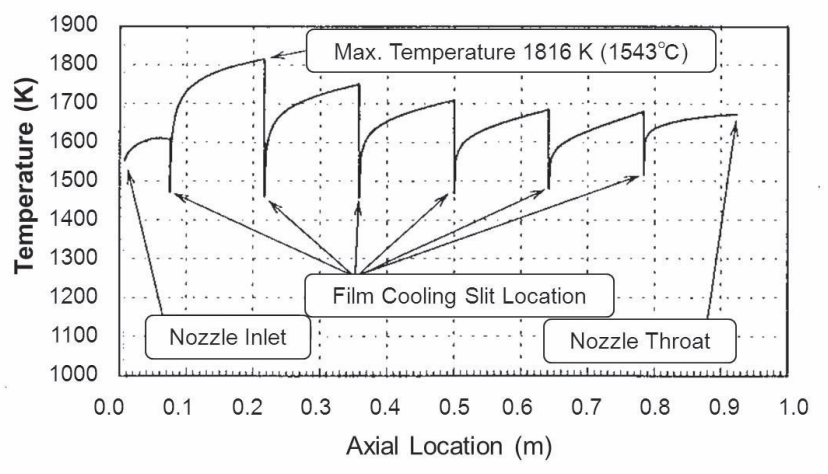

(a) Convergent Flap

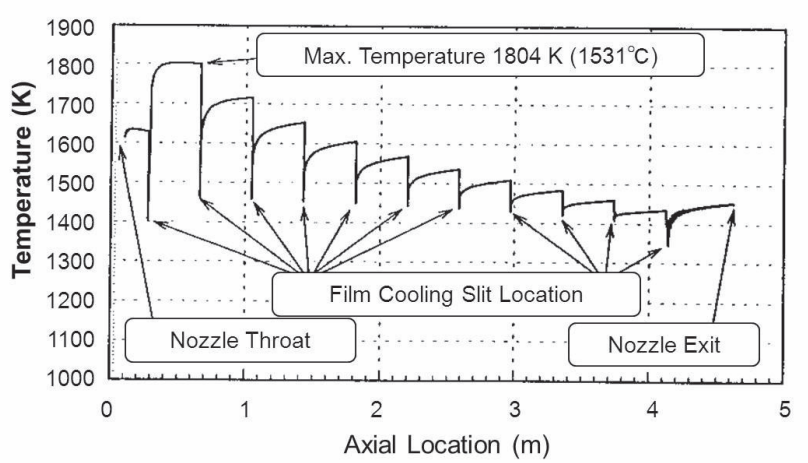

(b) Divergent Flap

Fig.12 Nozzle liner temperature prediction

\section{EXHAUST NOZZLE CONCEPT FOR MACH 5 HST}

Target exhaust nozzle system is proposed to be 2D-CD Ejector Nozzle, which has a function to eject intake bleed air into exhaust nozzle at throat. This concept makes it possible to reduce intake drag and minimize nozzle boat-tail drag. This system should be comprised of a couple of symmetrical convergent/divergent flaps and side walls, variable geometry mechanism, retractable mixer ejector as noise reduction device, and cooling structure [10]-[16]. Fig. 13 shows conceptual drawing of the nozzle system with straight divergent flaps [17]-[19].

Design point of aerodynamic passage will be Mach 5 cruise condition, and for off design flight condition aero passage will be changed to accommodate throat and exit area in order to get optimum thrust coefficient. Convergent and divergent flaps are operative independently by the actuating system on both sides of side wall plate.

At take-off mixer ejector will be moved to inside of nozzle passage for introduction of ambient air and mixing it with main gas flow in order to reduce exhaust jet velocity. However, during subsonic and supersonic cruise the mixer will be retracted on the back of convergent flap in order to avoid flow blockade or pressure loss. Figure 14 shows the schematic of nozzle configuration and variable geometry at Take-Off, Mach 3 and Mach 5 cruise conditions.

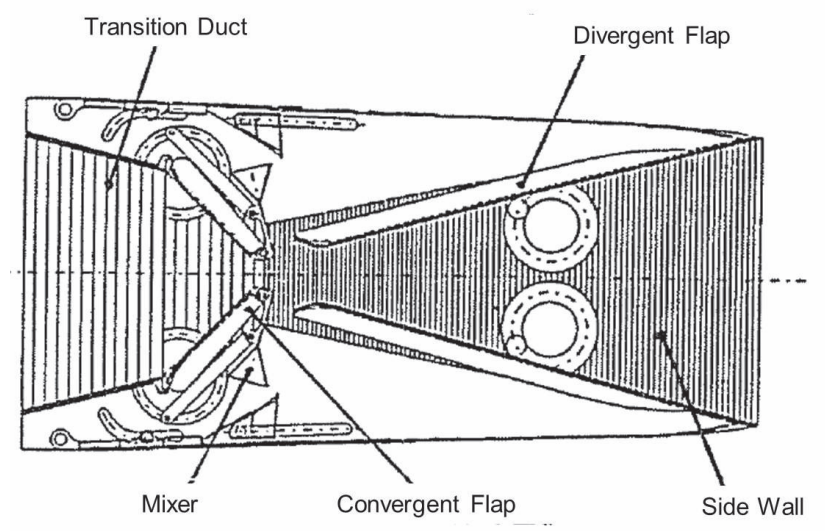

Fig.13 Concept of 2D-CD Exhaust Nozzle

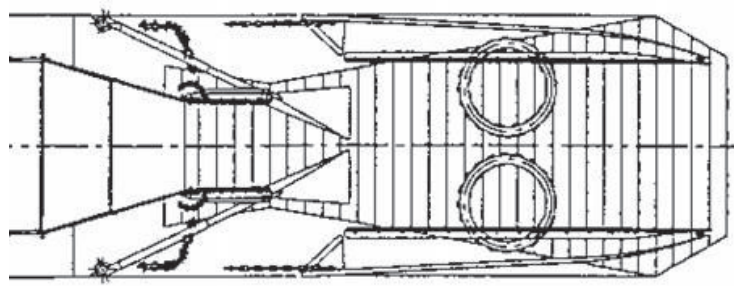

(a) Take-Off

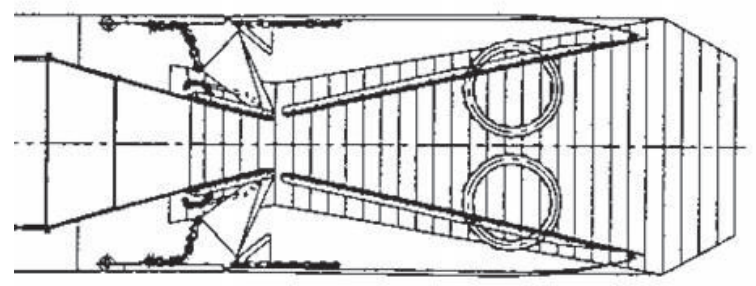

(b) Mach 3

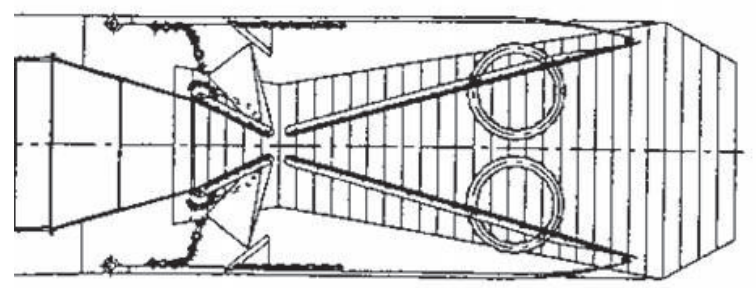

(c) Mach 5

Fig.14 The schematic of nozzle configuration and variable geometry at typical operational conditions 
Cooling structure will be adopted integrated film and impingement cooling scheme. Cooling air will be introduced from the exit of Ram Combustor cooling air. And if the pressure and air flow of cooling air are not sufficient for nozzle cooling, the intake bleed air will be used for cooling. In this case the intake bleed air will be pressurized by Auxiliary Power Unit (APU) and Air cooler (if necessary). Figure 15 shows Cooling system concept.

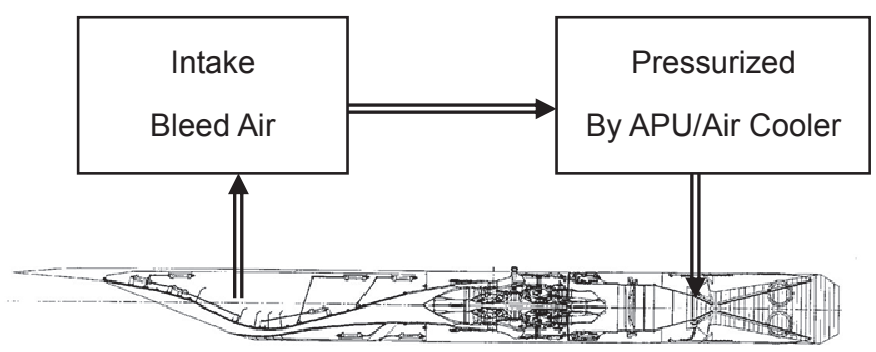

Fig. 15 Cooling System Concept

\section{CONCLUSIONS}

The outline of Exhaust Nozzle Research in Japanese HYPR Program is presented. Exhaust nozzle system for Mach 5 Hypersonic transport propulsion system is researched from aerodynamic, variable geometry mechanism and cooling structure point of view. In this study 2D-CD Ejector Nozzle is proposed as one of candidate concept. It is not only predicted that target performance of aerodynamic and cooling will be achieved, but also evaluated design technology and procedure of research and development for exhaust nozzle.

\section{ACKNOLEDGEMENT}

This study is conducted the entrustment contract with New Energy and Industrial Technology Development Organization (NEDO) as a part of the National Research and Development Program (Industrial Science and Technology Frontier Program) of Agency of Industrial Science and Technology (AIST) and Ministry of International Trade and Industry (MITI). The authors are grateful toward the NEDO for funding this study and authorizing this publication

\section{REFERENCES}

[1] Watanabe Y., Miyagi H., Sekido T., Miyagawa H. Aoki T., et al., "Conceptual Design Study on Combined-cycle Engine for Hypersonic Transport", ISABE 93-7066, September 1993

[2] Maingre E., Lamugue B., Joubert H., Kishi K., "CFD Optimization And Test Validation Of 2D Ramjet Nozzle For Hypersonic Vehicle", 30th AIAA/ASME/SAE/ASEE Joint Propulsion Conference, June 1994

[3] Donald W.Speir, Jack T.Blozy, "Internal Performance Prediction for Advanced Exhaust Systems", AIAA-81-1490

[4] William C.Strack, Shelby J.Morris Jr., "The Challenges and Opportunities of Supersonic Transport Propulsion Technology", AIAA 88-2985

[5] R.R.Schwab, F.A.Hewitt, "Optimization of Hybrid Propulsion Systems", European Symposium on Future Supersonic/Hypersonic Transportation System, November 1989

[6] Stephen J.Paul, Alex J.Giese, "Advanced Nozzle Cooling Concepts for Multi-Function Nozzle Durability", AIAA-89-2814

[7] D.O.Nash, T.G.Wakeman, J.L.Palcza, "Structural and Cooling Aspects of the Aden Nonaxisymmetric Exhaust Nozzle", ASME 77-GT-110

[8] W.H.Wooten, J.T.Blozy, D.W.Speir, R.A.Lotting, "Altitude Testing of a Flight Weight, Self-Cooled, 2D Thrust Vectoring Exhaust Nozzle", SAE 841557
[9] Kuchar A. P., and Wolf, J. P., "Preliminary Assessment of Exhaust Systems For High Mach (4 to 6) Fighter Aircraft", AIAA 89-2356, $25^{\text {th }}$ Joint Propulsion Conference, Monterey, 1989

[10] David M.Straight, Richard R.Cullom, "Thrust Performance of a Variable-Geometry, Nonaxisymmetric, Two-Dimensional, Convergent-Divergent Exhaust Nozzle on a Turbojet Engine at Altitude", NASA TP-2171

[11] D.J.Dusa, D.W.Speir, R.K.Rome, L.D.Leavitt, "Advanced Technology Exhaust Nozzle Development", AIAA-83-1286

[12] D.J.Dusa, "Exhaust Nozzle System Design Considerations for Turboramjet Propulsion Systems",AIAA-Invited Paper

[13] Victor Salemann, Lt.Mark Andrews, "Propulsion System Integration for Mach 4 to 6 Vehicles"

[14] James R.B.II, Linda S.B., John R.C., NASA-TP-2534, 1986

[15] D.J.Dusa, "Evaluation of Turbojet Exhaust System from Scale Model Test Data", ISABE 93-7109

[16] H.A.Geidel, "Improved Agility for Modern Fighter Aircraft, Part II Thrust Vectoring Engine Nozzles", ISABE 87-7062

[17] K.Kishi, T.Kashiwagi, M.Yamamoto, K.Tokunaga, H.Joubert, "Combined Nozzle Research", HYPR $2^{\text {nd }}$ International Symposium, October 19-20, 1995

[18] K.Kishi, T.Kashiwagi, M.Yamamoto, K.Tokunaga, H.Joubert, "Exhaust Nozzle Research in Japanese HYPR Program", AIAA95-2606, $31^{\text {st }}$ AIAA/ASME/SAE/ASEE Joint Propulsion Conferernce and Exhibit, July 10-12, 1995

[19] K.Kishi, M.Hirota, M.Yamamoto, H.Joubert, "Research of 2-D Variable Exhaust Nozzle", HYPR $3^{\text {nd }}$ International Symposium, May 19-20, 1999 